\title{
KERAGAMAN JENIS TANAMAN PADA SISTEM PENGELOLAAN HUTAN KEMASYARAKATAN
}

\author{
Diversity Of Plants In Community Forest Management Systems \\ Destia Novasari ${ }^{1}$, Rommy Qurniati ${ }^{1 *}$, Duryat ${ }^{1}$ \\ ${ }^{1} J u r u s a n$ Kehutanan, Universitas Lampung \\ Jl. Prof. Dr. Ir. Sumantri Brojonegoro No. 1, Bandar Lampung, Lampung \\ *Email: rommy.qurniati@gmail.com \\ Direvisi : 16/10/2019, Diterbitkan 02/03/2020
}

\begin{abstract}
Community Forestry is a government policy that aims to reduce the rate of deforestation by involving local communities through optimal, fair and sustainable use of forest resources while maintaining the preservation of forest and environmental functions. The diversity of plant species is one indicator of the preservation of forest and environmental functions. This study aims to determine the types of plants and cropping patterns carried out related to the characteristics of group members after obtaining Community Forest Utilization Permits. The study was conducted in December 2018. Data collection was carried out by structured interviews with members of the Sinar Harapan farmer group and direct observation in the field. Data is tabulated and analyzed descriptively. The results showed that the planting pattern used in Sinar Harapan group was a simple agroforestry pattern consisting of 8 types of intolerant plants namely avocado (Persea americana), petai (Parkia speciosa), areca nut (catechu area), durian (Durio zibethinus), jengkol (Archidendrom pauciflorum), bananas (Musaceae), candlenuts (Aleurites moluccanus), mahogany (Swietenia mahagoni) and 7 types of tolerant plants consisting of lemongrass (Cymbopogon citratus), cloves (Syzygium aromaticum), jaling (Archidendron bubalinum), chili (Capsicum frutescens) ), pepper (Piper Nigrum), nutmeg (Myristica fragrans), and coffee (Coffea). The diversity of plant species is influenced by age, type of work, activity in the organization, land area, and the number of working days of farmers.
\end{abstract}

Keywords; agroforestry; forest management; intolerant plant; tolerant plant.

\begin{abstract}
ABSTRAK
Hutan Kemasyarakatan merupakan kebijakan pemerintah yang bertujuan untuk menekan laju deforestasi dengan melibatkan masyarakat setempat melalui pemanfaatan sumber daya hutan secara optimal, adil dan berkelanjutan dengan tetap menjaga kelestarian fungsi hutan dan lingkungan hidup. Keragaman jenis tanaman merupakan salah satu indikator terjaganya kelestarian fungsi hutan dan lingkungan. Penelitian ini bertujuan untuk mengetahui jenis tanaman dan pola tanam yang dilakukan berkaitan dengan karakteristik anggota kelompok setelah mendapatkan Izin Usaha Pemanfaatan Hutan Kemasyarakatan. Penelitian dilakukan pada bulan Desember 2018. Pengumpulan data dilakukan dengan wawancara terstruktur terhadap anggota dan pengurus Gabungan Kelompok Tani (Gapoktan) Sinar Harapan dan observasi langsung di lapangan. Data ditabulasikan dan dianalisis secara deskriptif. Hasil penelitian menunjukan bahwa pola
\end{abstract}


tanam yang digunakan pada Gapoktan Sinar Harapan adalah pola agroforestri sederhana yang terdiri dari 8 jenis tanaman intoleran yaitu alpukat (Persea americana), petai (Parkia speciosa), pinang (Area catechu), durian (Durio zibethinus), jengkol (Archidendrom pauciflorum), pisang (Musaceae), kemiri (Aleurites moluccanus), mahoni (Swietenia mahagoni) dan 7 jenis tanaman toleran yang terdiri dari sereh (Cymbopogon citratus), cengkeh (Syzygium aromaticum), jaling (Archidendron bubalinum), cabai (Capsicum frutescens), lada (Piper nigrum), pala (Myristica fragrans), dan kopi (Coffea canephora). Keragaman jenis tanaman ini dipengaruhi oleh umur, jenis pekerjaan, keaktifan dalam organisasi, luas lahan, dan jumlah hari kerja petani.

Kata kunci; agroforestri; intoleran; pengelolaan hutan; toleran.

\section{PENDAHULUAN}

Tingginya jumlah penduduk dari tahun ketahun akan mengakibatkan berkurangnya sumberdaya alam sehingga ketahanan pangan semakin melemah. Tahun 2018 ketersediaan pangan berupa beras di Indonesia menurun, pada bulan Februari produksi beras Indonesia sebanyak 3,21 juta ton dengan jumlah konsumsi sebanyak 2,27 juta ton beras sedangkan pada bulan Desember jumlah produksi beras menurun menjadi 1,22 juta ton beras dengan besaran konsumsi 2,51 juta ton beras (BPS, 2018). Selain itu, pertambahan jumlah penduduk juga menyebabkan semakin berkurangnya lahan hutan dan pertanian akibat dari alih fungsi lahan menjadi pemukiman oleh masyarakat (Sanjaya dkk., 2017; Husen, 2017). Menurut data BPS tahun 2018, peningkatan jumlah penduduk sebanyak 1,36 juta pada tahun 2010-2016 dengan tingkat kerusakan lahan 1,1 juta hektar per tahun.

Adanya masalah tersebut dapat diminalisir dengan program Hutan Kemasyarakatan $(\mathrm{HKm})$ yang saat ini telah diterapkan diberbagai daerah. $\mathrm{HKm}$ merupakan kolaborasi antara kegiatan perlindungan, produksi hutan yang lestari serta kesejahteraan masyarakat sekitar hutan (Arifandy dan Sihaloho, 2015). HKm melarang petani melakukan penanaman dengan pola monokultur akan tetapi diarahkan untuk melakukan penanaman dengan pola polikultur atau agroforestri. Penerapan agroforestri pada suatu lahan dapat memenuhi kebutuhan pangan manusia serta mempertahankan keberadaan hutan. Hal ini dikarenakan penanaman dilakukan dengan menggabungkan jenis tanaman pertanian dan kehutanan pada satu areal lahan sehingga terciptanya produksi lestari bersama masyarakat yang sejahtera (Mayrowani dan Ashari, 2011).

Sinar Harapan merupakan gabungan kelompok tani yang telah mendapatkan izin usaha pemanfaatan HKm pada tahun 2014 dan berada di wilayah Kesatuan Pengelolaan Hutan (KPH) Batutegi. Melalui izin ini masyarakat dapat melakukan pemanfaatan sumber daya hutan secara optimal, adil dan berkelanjutan dengan tetap menjaga kelestarian fungsi hutan dan lingkungan hidup. Agar kelestarian fungsi hutan dan lingkungan hidup dapat terwujud maka perlu diidentifikasi keragaman jenis tanaman, pola tanam dan pengelolaan yang dilakukan oleh masyarakat pemegang izin $\mathrm{HKm}$. Penelitian ini bertujuan untuk menganalisi jenis tanaman, pola tanam, dan sistem pengelolaan lahan serta keterkaitanya dengan karakteristik anggota Gabungan Kelompok Tani (Gapoktan) Sinar Harapan.

\section{METODE}

Penelitian ini dilakukan di Gapoktan Sinar Harapan pada bulan Desember 2018. Area kerja Gapoktan ini berada di KPH Batutegi Provinsi Lampung. Penelitian ini 
menggunakan data primer dan data sekunder. Data primer yang terdiri dari karakteristik responden, jenis tanaman, pola tanam dan pengelolaan lahan yang diambil menggunakan metode wawancara pada 42 responden dan observasi langsung di lahan HKm. Data sekunder terdiri dari data kelompok tani Gapoktan Sinar Harapan dan gambaran umum area $\mathrm{HKm}$. Data diolah dalam bentuk tabulasi dan dianalisis keterkaitannya antara sistem pengelolaan lahan dengan karakteristik responden serta jenis tanaman yang ada menggunakan metode analisis deskriptif.

\section{HASIL dan PEMBAHASAN}

Berdasarkan hasil penelitian umur petani didominasi oleh umur produktif kerja yaitu 18-65 tahun. Petani pada umur produktif kerja memungkin untuk melakukan pengelolaan lebih baik dibandingkan petani dengan umur tidak produktif kerja. Hal ini karena semakin muda seseorang maka akan semakin tinggi curahan tenaga kerja dan tingkat kreatifitasnya. Sejalan dengan pendapat Winarni (2016) yang menyatakan bahwa petani dengan umur produktif akan semakin tinggi kemampuan yang dimiliki. Data kelompok umur dan karakteristik lainnya dari anggota Gapoktan Sinar Harapan disajikan pada Tabel 1.

Tabel 1. Karakteristik Anggota Gapoktan Sinar Harapan

Table 1. Characteristics of Sinar Harapan Group Member

\begin{tabular}{|c|c|c|c|}
\hline \multirow{2}{*}{ No } & \multirow{2}{*}{ Variabel } & \multicolumn{2}{|c|}{ Gapoktan Sinar Harapan } \\
\hline & & Jumlah (orang) & Persentase (\%) \\
\hline \multirow[t]{3}{*}{1} & Kelompok umur (th) & & \\
\hline & $18-65$ & 49 & $98 \%$ \\
\hline & $>65$ & 1 & $2 \%$ \\
\hline \multirow[t]{4}{*}{2} & Tingkat pendidikan & & \\
\hline & Tidak sekolah & & - \\
\hline & Pendidikan dasar & 40 & $80 \%$ \\
\hline & Pendidikan menengah & 10 & $20 \%$ \\
\hline \multirow[t]{5}{*}{3} & Luas lahan garapan & & \\
\hline & $<1$ & 2 & $4 \%$ \\
\hline & $1-2$ & 39 & $78 \%$ \\
\hline & $2,5-4$ & 5 & $10 \%$ \\
\hline & $>4$ & 4 & $8 \%$ \\
\hline \multirow[t]{4}{*}{4} & Jumlah hari kerja/ minggu & & \\
\hline & $1-3$ & 0 & 0 \\
\hline & 4- 6 & 37 & $74 \%$ \\
\hline & 7 & 13 & $26 \%$ \\
\hline \multirow[t]{3}{*}{5} & Status dalam Gapoktan & & \\
\hline & Aktif & 44 & $88 \%$ \\
\hline & Pasif & 6 & $12 \%$ \\
\hline \multirow[t]{4}{*}{6} & Jumlah tanggungan keluarga (orang) & & \\
\hline & $0-2$ & 24 & $48 \%$ \\
\hline & $3-4$ & 23 & $46 \%$ \\
\hline & $>4$ & 3 & $6 \%$ \\
\hline \multirow[t]{3}{*}{7} & Jenis pekerjaan & & \\
\hline & Bertani kopi & 46 & $92 \%$ \\
\hline & $\begin{array}{l}\text { Bertani kopi dan pekerjaan tambahan } \\
\text { lain }\end{array}$ & 4 & $8 \%$ \\
\hline \multirow[t]{2}{*}{8} & Lama bertani (tahun) & & \\
\hline & $1-5$ & 26 & $52 \%$ \\
\hline
\end{tabular}




$\begin{array}{lcc}6-10 & 10 & 20 \% \\ >10 & 14 & 28 \% \\ 9 \text { Cara mendapatkan lahan } & 11 & 22 \% \\ \text { Warisan } & 4 & 8 \% \\ \text { Ganti rugi tenaga } & 35 & 70 \% \\ \text { Buka lahan } & \end{array}$

Sumber : Data Primer Diolah Tahun 2019

Tingkat pendidikan petani juga mempengaruhi keberhasilan petani dalam berusahatani. Tabel 1 menunjukkan bahwa sebagian besar tingkat pendidikan petani masih pada tahap pendidikan dasar. Pendidikan dasar meliputi pendidikan pada sekolah dasar dan sekolah menengah pertama. Padahal Achmad dan Diniyanti (2015) menyatakan bahwa semakin tinggi tingkat pendidikan maka semakin luas pola pikir seseorang. Terbatasnya tingkat pendidikan petani di Gapoktan Sinar Harapan membatasi pola pikir petani pada ragam pekerjaannya.

Sebagian besar petani mengandalkan penghasilannya dari lahan HKm. Hanya sebagian kecil saja yang memiliki pekerjaan tambahan selain bertani. Pekerjaan lain selain bertani yang dijalani terdiri dari Wirausaha, ojek, buruh, PNS, pedamping desa dan pengurus kelompok sadar wisata. Hal ini diduga berpengaruh terhadap keberhasilan pengelolaan hutan yang dilakukan. Adanya pekerjaan tambahan lain selain bertani berhubungan dengan tingkat partisipasinya dalam melakukan pengelolaan hutan sehingga terdapat hubungan antara jenis pekerjaan dengan sistem pengelolaan hutan. Tingkat ketergantungan petani terhadap lahan akan semakin tinggi jika hanya memiliki pekerjaan sebagai penggarap lahan hutan saja (Sudhartono., dkk, 2011).

Tingkat ketergantungan terhadap lahan juga dipengaruhi oleh jumlah tanggungan keluarga, dimana rata-rata petani memiliki tanggungan 0-4 orang. Semakin banyak jumlah tanggungan keluarga maka akan semakin besar jumlah pengeluaran yang dilakukan. Selaras dengan hasil penelitian Robiyan., dkk (2014) yang menyatakan bahwa besaran pengeluaran setiap keluarga dipengaruhi oleh jumlah tanggungan keluarga. Akan tetapi beban tanggungan ini dapat diimbangi jika jumlah tanggungan keluarga dapat dijadikan sebagai tenaga kerja dalam pengelolaan lahan garapan seperti yang dijelaskan oleh Senoaji (2009) bahwa jumlah tanggungan keluarga dapat menjadi aset untuk kepala keluarga.

Petani Gapoktan Sinar Harapan memiliki anggota yang aktif dalam organisasi, hanya sebagian kecil anggota yang tidak aktif. Keaktifan petani dalam organisasi mempengaruhi kapasitas yang dimiliki sehingga menentukan tingkat keberhasilan petani dalam mengelola hutan. Petani yang aktif dalam organisai juga dapat menjalin hubungan yang baik antar petani lain. Hal ini terbukti dalam Gapoktan Sinar Harapan, petani yang aktif dalam organisasi akan menjalin hubungan yang baik antar petani. Hubungan yang baik terlihat dari cara mengelola lahan dengan gotong royong sesama penggarap lahan secara bergantian sehingga terlihat adanya korelasi antara keaktifan anggota dalam organisasi dengan pengelolaan lahan (Salampessy., dkk, 2012).

Luas lahan garapan petani terbagi menjadi tiga kategori yaitu sempit, sedang, dan luas. Penggolongan ini mengacu pada Manyamsari dan Mujiburrahmad (2014); lahan sempit yaitu lahan dengan luasan kurang dari 1 ha, luas lahan 1-2 ha tergolong sedang, dan lebih dari 2 ha tergolong luas. Sebagian besar petani gapoktan menggarap lahan seluas 1-2 ha dengan kategori sedang. Luas lahan dapat menentukan tingkat partisipasi petani dalam pengelolaannya. Petani dengan lahan yang semakin sempit akan meningkatkan ketekunannya dalam melakukan pengelolaan karena dengan lahan yang sempit petani harus mendapatkan hasil produksi yang maksimal agar dapat memenuhi 
kebutuhan hidup sehingga semakin sempit lahan garapannya maka petani akan semakin tinggi ketergantungan hidupnya terhadap lahan (Sudhartono., dkk, 2011).

Petani Gapoktan Sinar Harapan sebagian besar telah mengelola lahan selama 1-5 tahun sehingga masih tergolong baru. Petani yang baru terjun dalam pengelolaan lahan mendapatkan lahan garapannya dengan cara membuka lahan baru. Tidak hanya membuka lahan baru sebagian petani juga mendapatkan lahan garapan pemberian dari orang tua dan ganti rugi tenaga. Banyaknya lahan garapan yang baru dibuka mengakibatkan tingginya waktu kerja petani dalam pengelolaan untuk mencapai hasil yang diinginkan. Sehingga terlihat bahwa petani menggunakan 4-7 hari dalam satu minggu untuk bekerja dilahan. Semakin sering petani masuk ke lahan maka lahan akan semakin baik karena setiap masuk lahan petani melakukan pengelolaan lahan seperti pemelliharaan tanaman.

Pembukaan lahan garapan baru setelah terbitnya Izin Usaha Pemanfaatan HKm (IUPHKm) perlu menjadi perhatian serius. Karena IUPHKm diterbitkan dengan luasan area kelola yg telah ditentukan, artinya tidak boleh ada penambahan lahan garapan baru pada Gapoktan ini. Pemahaman masyarakat tentang konsep HKm perlu ditingkatkan lagi, agar izin $\mathrm{HKm}$ tidak disalah gunakan untuk membuka hutan sebagi lahan garapan yang baru.

Petani Gapoktan Sinar Harapan melakukan penanaman dengan sistem agroforestri sederhana. Sistem agroforestri sederhana merupakan pola tanam yang menggabungkan tanaman kehutanan dengan tanaman semusim (pertanian) (Tjatjo., dkk, 2015). Tanaman yang ada dilahan merupakan tanaman Multy Purpose tree Species (MPTS) dan kayukayuan diantara tanaman petanian dengan tanaman utama yaitu kopi (Coffea canephora). Petani menganggap kopi sebagai tanaman yang paling menguntungkan dibandingkan tanaman semusim lainnya seperti durian karena kopi memberikan hasil yang pasti setiap tahunnya.

Tabel 2. Jenis, Umur, dan Jumlah Tanaman di Gapoktan Sinar Harapan Table 2. Species, Age, and Number of Plants in Gapoktan Sinar Harapan

\begin{tabular}{llcc}
\multicolumn{1}{c}{ Nama } & Jenis Tanaman & \multicolumn{2}{c}{ Sinar Harapan } \\
\multicolumn{1}{c}{ Lokal } & \multicolumn{1}{c}{ Nama Latin } & $\begin{array}{c}\text { Rata-rata umur } \\
\text { (th) }\end{array}$ & $\begin{array}{c}\text { Rata-rata jumlah batang/ } \\
\text { ha }\end{array}$ \\
\hline Kopi & Coffea canephora & 7,5 & 2890 \\
Alpukat & Persea americana & 5,06 & 12 \\
Petai & Parkia speciosa & 4,6 & 13 \\
Nangka & Artocarpus heterophyllus & 0 & 0 \\
Pinang & Areca catechu & 6,3 & 83 \\
Durian & Durio zibethinus & 6,7 & 15 \\
Coklat & Theobroma cacao & 0 & 0 \\
Pala & Myristica fragrans & 3 & 38 \\
Jengkol & Archidendron & 5,8 & 31 \\
& pauciflorum & 7,2 & 496 \\
Lada & Piper nigrum & 0,8 & 79 \\
Pisang & Musaceae & 0,32 & 376 \\
Cabai & Capsicum frutescens & 0 & 0 \\
Pepaya & Carica papaya & 2,5 & 18 \\
Jaling & Archidendron bubalinum & 6,25 & 51 \\
Cengkeh & Syzygium aromaticum & 9,8 & 22 \\
Kemiri & Aleurites moluccanus & 20 & 6 \\
Mahoni & Swietenia mahagoni & &
\end{tabular}


Sereh Cymbopogon citratus 0,05 19

Sumber: Data Primer Diolah Pada Tahun 2019

Berdasarkan jenis tanaman yang ada maka dapat digolongkan menjadi tanaman intoleran dan tanaman toleran. Jenis pohon intoleran terdiri dari alpukat (Persea americana), petai (Parkia speciosa), pinang (Area catechu), durian (Durio zibethinus), jengkol (Archidendrom pauciflorum), pisang (Musaceae), kemiri (Aleurites moluccanus), mahoni (Swietenia mahagoni). Sedangkan tanaman toleran meliputi sereh (Cymbopogon citratus), cengkeh (Syzygium aromaticum), jaling (Archidendron bubalinum), cabai (Capsicum frutescens), lada (Piper nigrum), pala (Myristica fragrans), dan kopi (Coffea canephora). Tanaman dengan tajuk yang tebal dan rapat merupakan jenis tanaman intoleran dan tanaman yang memiliki tajuk yang tipis dan jarang adalah jenis tanaman toleran (Pratiwi., dkk, 2013).

Tidak semua jenis tanaman intoleran sesuai dengan kebutuhan tanaman utama Gapoktan Sinar Harapan. Hal ini juga ditemukan pada penelitian Evrizal., dkk, (2016) dan Ruchyansyah., dkk, (2018), bahwa beberapa jenis yang ditanam petani di lahan HKm merupakan jenis intoleran seperti cengkeh, pala, dan kemiri. Petani tetap menanam jenisjenis yang intoleran terhadap tanaman utama karena tanaman intoleran tersebut dapat memberikan tambahan hasil bagi petani.

Pendapatan rata-rata per keluarga petani di Gapoktan Sinar Harapan sebesar Rp 46. 350.000,-/tahun atau Rp 3.862.500,-/bulan. Pendapatan ini diperoleh dari penjualan kopi (Coffea canephora), lada (Piper nigrum), dan pisang (Musaceae). Hasil HKm yang dominan menyumbang pada pendapatan adalah kopi. Hasil dari jenis tanaman lain hanya dimanfaatkan secara subsisten karena jumlahnya tidak banyak.

\section{KESIMPULAN}

Karakteristik petani seperti sistem pengelolaan hutan adalah umur, jenis pekerjaan, keaktifan dalam organisasi, luas lahan, dan jumlah hari kerja petani mempengaruhi penentuan jenis dan pengelolaan lahan yang dikembangkan di lahan HKm. Gapoktan Sinar Harapan memiliki 8 jenis tanaman intoleran dan 7 jenis tanaman toleran yang membentuk pola tanam sistem agroforestri sederhana. Tanaman toleran yang ada terdiri dari tanaman alpukat (Persea americana), petai (Parkia speciosa), pinang (Area catechu), durian (Durio zibethinus), jengkol (Archidendrom pauciflorum), pisang (Musaceae), kemiri (Aleurites moluccanus), mahoni (Swietenia mahagoni). Tanaman toleran yang ada terdiri dari dari sereh (Cymbopogon citratus), cengkeh (Syzygium aromaticum), jaling (Archidendron bubalinum), cabai (Capsicum frutescens), lada (Piper nigrum), pala (Myristica fragrans), dan kopi (Coffea canephora).

\section{DAFTAR PUSTAKA}

Achmad, B. \& Diniyati, D. (2015). Keragaman jenis tanaman dan pengelolaannya pada hutan rakyat di Kabupaten Ciamis, Jawa Barat. Pros. Semnas Masy Indn, 1(3), 460465.

Arifandy, M.I \& Sihaloho, M. (2015). Efektivitas pengelolaan hutan bersama masyarakat sebagai resolusi konflik sumber daya hutan. Jurnal Sosiologi Pedesaan, 3(2), 147-158.

Badan Pusat Statistika. (2018). Luas Panen dan Produksi Beras di Indonesia 2018. Diunduh dari https://www.bps.go.id/.../2018/.../luas-panen-dan-produksi-beras. 
Badan Pusat Statistika. (2018). Statistika Indonesia 2018. Diunduh dari https://www.bps.go.id/.../2018/07/03/../statistik-indonesia-2018.

Evrizal, R., Sugiatno., Prasmatiwi F.E. \& Nurmayasari, I. (2016). Shade tree species diversity and coffee productivity in Sumberjaya, West Lampung, Indonesia. Jurnal Biodiversitas, 17(1), 234-240.

Manyamsari, I. \& Mujiburrahmad. (2014). Karakteristik petani dan hubungannya dengan kompetensi petani lahan sempit (kasus : di Desa Sinar Sari Kecamatan Dramaga Kab. Bogor Jawa Barat). Jurnal Agrisep, 15(2), 58-74.

Mayrowani, H. \& Ashari. (2011). Pengembangan agroforestry untuk mendukung ketahanan pangan dan pemberdayaan petani sekitar. Forum penelitian agro ekonomi, 29(2), 8398.

Pratiwi, Y.Y., Bintoro, A. \& Riniarti, M. (2013). Komposisi dan Struktur Tegakan Zona Pemanfaatan Terbatas SPTN 1 Way Kanan, Taman Nasional Way Kambas. Makalah disajikan dalam Seminar Nasional Sains dan Teknologi V, Lembaga Penelitian Universitas Lampung, Lampung, 19-20 November.

Ruchyansyah, Y., Wulandari, C. \& Riniarti, M. (2018). Pengaruh pola budidaya pada hutan kemasyarakatan di areal kelola KPH VIII Batutegi terhadap pendapatan petani dan kesuburan tanah. Jurnal Sylva Lestari, 6(1), 99-108.

Salampessy, M.L., Nugroho, B. \& Purnomo, H. (2012). Hubungan karakteristik responden dengan partisipasi masyarakat dalam kegiatan pengelolaan hutan lindung Gunung Nona di Kota Ambon Propinsi Maluku. Jurnal Penelitian Sosial dan Ekonomi Kehutanan, 9(3), 149-159.

Sanjaya, R., Wulandari, C. \& Herwanti, S. (2017). Evaluasi pengelolaan Hutan Kemasyarakatan ( $\mathrm{Hkm}$ ) pada Gabungan Kelompok Tani Rukun Lestari Sejahtera di Desa Sindang Pagar Kecamatan Sumberjaya Kabupaten Lampung Barat. Jurnal Sylva Lestari, 5(2), 30-42.

Senoaji, G. (2009). Kontribusi hutan lindung terhadap pendapatan masyarakat desa di sekitarnya: studi kasus di Desa Air Lanang Bengkulu. Jurnal Manusia dan Lingkungan, 16(1), $12-22$.

Sudhartono, A., Basuni, S., Bahruni. \& Suharjit, D. (2011). Pola akses petani penggarap lahan di kawasan perluasan Taman Nasional Gunung Gede Pangrango Jawa Barat. Jurnal IImiah Bidang Konservasi Sumberdaya Alam Hayati dan Lingkungan, 16(3), 122-132.

Tjatjo., N.T., Basir, M. \& Umar, H. (2015). Karakteristik pola agroforestri masyarakat di Sekitar Hutan Desa Namo Kecamatan Kulawi Kabupaten Sigi. Jurnal Sains dan Teknologi Tadulako, 4(3), 55-64.

Winarni, S., Yuwono, S. B. \& Herwanti, S. (2016). Struktur pendapatan, tingkat kesejahteraan dan faktor produksi agroforestri kopi pada Kesatuan Pengelolaan Hutan Lindung Batutegi (studi di Gabungan Kelompok Tani Karya Tani Mandiri). Jurnal Sylva Lestari, 4(1), 1-10. 